\title{
Measles activity in Canada: January - June 2014
}

\author{
Deehan $\mathrm{H}^{1 *}$ and Shane $\mathrm{A}^{1}$
}

1 Public Health Agency of Canada

* Corresponding author: Heather.Deehan@phac-aspc.gc.ca

\begin{abstract}
Since the beginning of 2014 to May 10, 103 cases of measles have been reported to the Public Health Agency of Canada from five provinces: British Columbia, Alberta, Saskatchewan, Manitoba and Ontario. Three factors contribute to this. First, Canadians travel more than they used to, increasing the risk in those who are not immunized of importing the disease into Canada. Second, there has been an increase in measles in countries that have high population exchange with Canada, including France (2011), the Netherlands (2013) and, most recently, the Philippines (2014). Finally, there is suboptimal immunization coverage in some areas across Canada. This year there have been 21 importations to May 10th, yet, despite how highly contagious measles is, only eight led to transmission within Canada. Strengthening immunization programs, maintaining heightened vigilance and continuing to achieve rapid containment of imported infections are essential for sustaining measles elimination.
\end{abstract}

\section{Introduction}

Despite the achievement of measles elimination in Canada, importations of measles cases and subsequent secondary spread are expected as long as measles remains endemic in other parts of the world. The following is a brief summary of Canadian measles activity in 2014.

\section{Epidemiologic summary}

Since the beginning of 2014 (epidemiologic week 1: December 30, 2013, to epidemiologic week 19: May 10, 2014), 103 cases of measles have been reported to the Public Health Agency of Canada (the Agency) through the Canadian Measles and Rubella Surveillance System. Cases have been reported from five provinces: British Columbia $(n=36)$, Alberta $(n=24)$, Saskatchewan $(n=16)$, Manitoba $(n=8)$ and Ontario $(n=19)$. Fraser Health Authority, British Columbia, has notified the Agency and the public of a large outbreak in the Fraser East area, where there are an estimated 423 cases; most of these have yet to be reported through the national surveillance system.

To date, 21 importations have been reported from six countries. The majority of the importations are from the Philippines ( $n=15,71 \%)$, where there has been a large outbreak of measles, but cases have also been imported from India $(n=2)$, the United States $(n=1)$, Thailand $(n=1)$, Pakistan $(n=1)$ and Italy/Amsterdam $(n$ $=1$ ). The number of measles importations to Canada has remained relatively stable over the years, with a median of 5 per year from 1998 to 2009. However, increases have been observed recently in 2010 ( $n=10$, Olympic year), $2011(n=29)$ and $2013(n=12)$. Changes in both travel patterns and the global incidence of measles activity are two contributing factors that may explain the increase in importations.

In 2000, Canadian residents took an estimated 4.5 million trips overseas while overseas visitors (non-residents) made 4.4 million trips to Canada (1). In 2012, Canadians took an estimated 11 million trips outside the country (excludes trips to the USA) (2), which represents a 2.5 fold increase in overseas travel. Comparison with the Canadian population increase of only $13 \%$ over the same period suggests that this travel increase is not only related to population growth (3).

A second contributor is increased measles incidence in countries that have high population exchange with Canada. For example, large outbreaks of measles in France (2011) (4), the Netherlands (2013) (5) and the Philippines (2014) (6) may account for the increase in measles importations to Canada. 
Secondary spread of most importations has been limited in 2014. Of the 21 importations reported to May 10 , eight have led to transmission within Canada. Of the five outbreaks that had concluded at the time of writing, the median duration between rash onset dates of the first and last cases was 20 days (range: 13 to 35), and the median number of cases was 3 (range 2 to 10$)$. Of imported cases, the majority were unimmunized $(n=12$, $57 \%)$ or had unknown immunization history $(n=4,19 \%)$, the remainder having received one $(n=1,5 \%)$ or two doses $(n=4,19 \%)$ of measles-containing vaccine. The age distribution of measles cases by source of exposure is found in Figure 1.

Figure 1. Age distribution of confirmed measles cases by exposure source, Canada, December 30, 2013, to May 10, 2014 ( $n=103)$

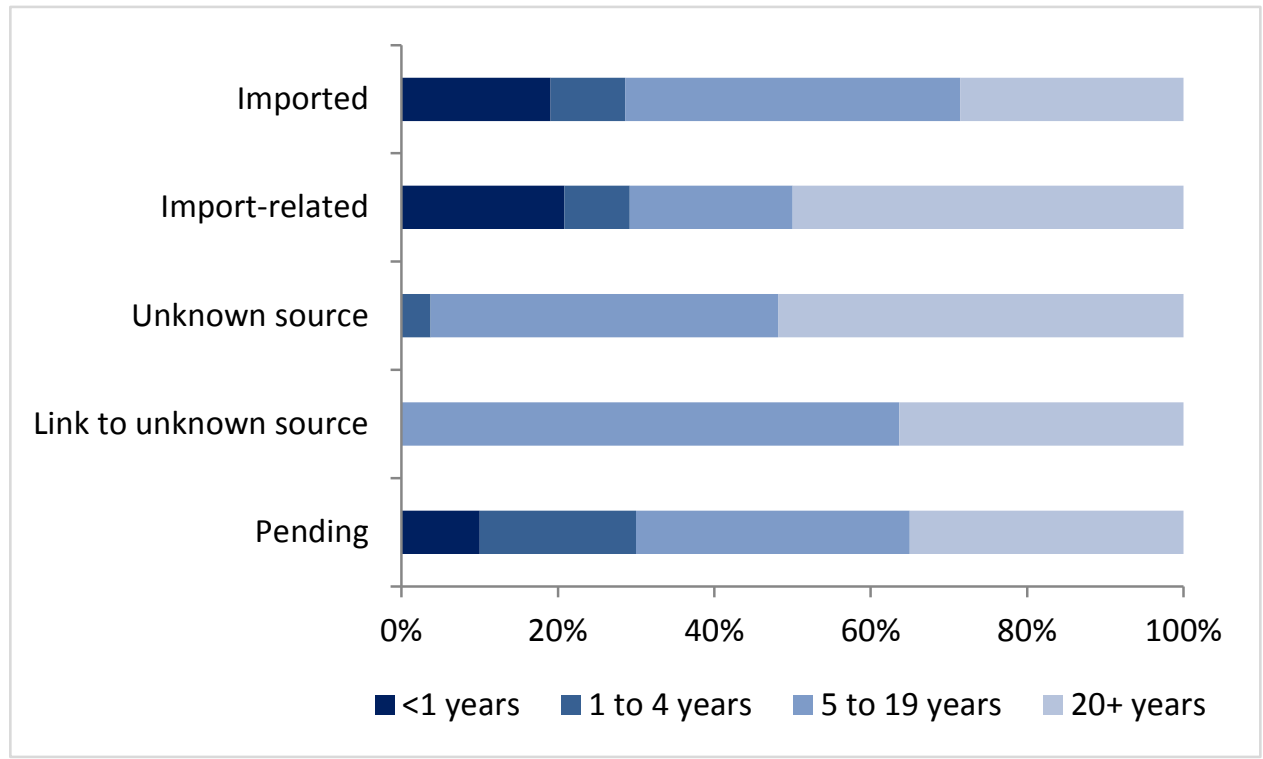

\section{Limitations}

The information provided in this rapid communique is limited to what has been reported to the Agency through the Canadian Measles/Rubella Surveillance System or the Measles and Rubella Surveillance system pilot by May 10, 2014. Therefore, there may be inconsistencies with data reported by provinces and territories. A data audit is conducted annually with provinces and territories to validate measles data reported to the Agency.

\section{Canada's Plan of Action for maintaining measles elimination}

Canada does recognize that the threat of imported measles, combined with suboptimal immunization coverage in some areas, poses a risk of re-introduction and domestic transmission, as experienced during the 2011 measles outbreaks that threatened Canada's elimination status. Strengthening immunization programs, maintaining heightened vigilance and rapid containment of imported infections are essential for sustaining measles elimination.

For Canada to sustain measles and rubella elimination, all jurisdictions will need to continue to strengthen collaboration and support high-quality immunization programs. The Agency plans to consult with provincial and territorial partners and other experts, nationally and internationally, to develop and implement a multi-year Plan of Action building on earlier accomplishments, to ensure that measles elimination is sustained.

\section{References}

(1) King A, Varughese P, De Serres G, Tipples GA, Waters J, Working Group on Measles Elimination. Measles elimination in Canada. J Infect Dis. 2004;189 Suppl 1:S236-42. doi: 10.1086/378499. 
(2) Statistics Canada. International travel survey, Canadian residents 2008-2012, custom extract for the Public Health Agency of Canada. 2014.

(3) Statistics Canada, demography division, demographic estimates section, July population estimates, 2011 final intercensal estimate.

(4) World Health Organization European Region. Centralized information system for infectious diseases. http://data.euro.who.int/cisid/.

(5) Knol MJ, Urbanus AT, Swart EM, et al. Large ongoing measles outbreak in a religious community in the Netherlands since May 2013. Eurosurveillance. 2013;18(36).

(6) World Health Organization Western Pacific Region. Measles-rubella bulletin April 2014. http://www.wpro.who.int/immunization/documents/MRBulletinVol8Issue04.pdf?ua=1. 